\title{
Treadmill exercise enhances spatial learning ability through suppressing hippocampal apoptosis in Huntington's disease rats
}

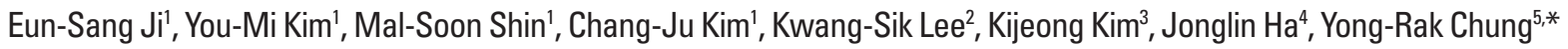 \\ 'Department of Physiology, College of Medicine, Kyung Hee University, Seoul, Korea \\ ${ }^{2}$ Research Institute of Sports Science, National University of Incheon, Incheon, Korea \\ ${ }^{3}$ Department of Exercise \& Sport Science, College of Natural Sciences, University of Ulsan, Ulsan, Korea \\ ${ }^{4}$ Department of Anesthesiology and Pain Medicine, CHA Bundang Medical Center, CHA University, Seongnam, Korea \\ ${ }^{5}$ Department of Golf Mapping, College of Arts Physical Education, Joongbu University, Geumsan-gun, Chungcheongnam-do, Korea
}

Huntington's disease is a chronic neurodegenerative disorder inherited in an autosomal dominant fashion, and characterized as involuntary movement. Quinolinic acid has been used to produce an animal model of Huntington's disease. In the present study, the effect of treadmill exercise on spatial-learning ability and motor coordination focusing on the apoptosis in the hippocampus was investigated using quinolinic acid-induced Huntington's disease rats. Huntington's disease was induced by unilateral intrastriatal injection of quinolinic acid $(2 \mu \mathrm{L}$ of $100 \mathrm{nmol})$ using stereotaxic instrument. The rats in the treadmill exercise groups were subjected to run on a treadmill for 30 min once a day during 14 days. Spatial learning ability and motor coordination were determined by radial 8-arm maze test and rota-rod test. Immunohistochemistry for caspase-3 and western blot for Bax and Bcl-2 were also conducted for the detection of apoptosis. In the present results, spatial learning ability and motor coordination were deteriorated by intrastriatal injection of quinolinic acid. In contrast, treadmill exercise exerted ameliorating effect on quinolinic acid-induced deterioration of spatial learning ability and motor coordination. Bcl-2 expression in the hippocampus was decreased and expressions of casepase- 3 and Bax in the hippocampus were increased in the quinolinic acid-induced Huntington's disease rats. Treadmill exercise increased $\mathrm{Bcl}-2$ expression and decreased expressions of casepase- 3 and Bax in the Huntington's disease rats. The present results showed that treadmill exercise might ameliorate quinolinic acid-induced loss of spatial learning ability and motor coordination by suppressing apoptosis in the hippocampus.

Keywords: Huntington's disease, Quinolinic acid, Treadmill exercise, Spatial learning ability, Motor coordination, Apoptosis

\section{INTRODUCTION}

Huntington's disease is a chronic neurodegenerative disorder inherited in an autosomal dominant fashion, and characterized as involuntary movement (Schwarcz et al., 2010). Excitoxicity has been suggested as the inducing factor of the neurodegeneration associated with Huntington's disease (Estrada Sánchez et al., 2008). Quinolinic acid is an N-methyl-D-aspartate receptor agonist, and administration of quinolinic acid into the animals produces neurotoxic effects, and then causes symptoms of several neurodegenerative diseases, such as Alzheimer's disease, Parkinson's disease, and more commonly Huntington's disease (Haik et al., 2000). Intrastriatal injection of quinolinic acid produced cell death that mimics neuronal loss seen in Huntington's disease patients (Beal et al., 1986). Quinolinic acid has been used to produce an animal model of Huntington's disease (Jørgensen et al., 2011; Kim et al., 2015).

Apoptosis is a form of cell death that constitutes part of a common mechanism in cell replacement, tissue remodeling, and removal of damaged cells (Thompson, 1995). A class of cysteine
${ }^{*}$ Corresponding author: Yong-Rak Chung

Department of Golf Mapping, College of Arts Physical Education, Joongbu University, 201 Daehak-ro, Chubu-myeon, Geumsan-gun, Chungcheongnam-do 312-702, Korea

Tel: +82-41-750-6585, Fax: +82-41-750-6587, E-mail: yrjung@joongbu.ac.kr

Received: June 5, 2015 / Accepted: June 8, 2015
This is an Open Access article distributed under the terms of the Creative Commons Attribution Non-Commercial License (http://creativecommons.org/licenses/by-nc/3.0/) which permits unrestricted non-commercial use, distribution, and reproduction in any medium, provided the original work is properly cited. 
proteases, such as caspase- 3 , caspase- 8 , and caspase-9, is commonly involved in the apoptotic pathways (Nuñez et al., 1998). Besides caspases, the $\mathrm{Bcl}-2$ family also plays an important role in the regulation of apoptosis. $\mathrm{Bcl}-2$ proteins are classified into anti-apoptotic proteins, which include Bcl-2 and Bcl-2 XL, and pro-apoptotic proteins, such as Bax and Bid (Kuwana and Newmeyer, 2003). Excessive neuronal apoptosis contributes to the dysfunction of the central nervous system (Baek et al., 2012; Kuhn et al., 2005). Inappropriate activation of apoptosis has been implicated in the pathogenesis of several chronic age-related neurological disorders, including Huntington's disease (Petersén et al., 1999). Furthermore, in vitro studies have provided evidence for a link between apoptosis and the mutant huntingtin protein (Hickey and Chesselet, 2003).

Exercise enhances learning ability and memory functions, protects from neurodegeneration, and alleviates symptoms of neuropsychiatric disorders (Kim et al., 2010; 2011; Seo et al., 2013). Neuroprotective effects of exercise on various brain insults are well documented (Kim et al., 2011; Lang et al., 2010; Petrus et al., 2008). However, the effects of exercise on Huntington's disease in relation with apoptosis are not clarified.

In the present study, we evaluated the effect of treadmill exercise on spatial learning ability and motor coordination focusing on the apoptosis in the hippocampus using quinolinic acid-induced Huntington's disease rats. For this study, spatial learning ability and motor coordination were determined by radial 8-arm maze test and rota-rod test. Immunohistochemistry for caspase-3 and western blot for $\mathrm{Bax}$ and $\mathrm{Bcl}-2$ were also conducted for the detection of apoptosis.

\section{MATERIALS AND METHODS}

\section{Animals}

Female Sprague-Dawley rats ( $210 \pm 10 \mathrm{~g}, 6$ weeks old) were used, and the experimental procedures were performed in accordance with the animal care guidelines of the National Institute of Health (NIH) and the Korean Academy of Medical Sciences. The animals were housed under the controlled temperature $\left(23 \pm 2^{\circ} \mathrm{C}\right)$ and lighting (08:00 to 20:00 h) conditions with food and water available ad libitum. The animals were randomly divided into four groups ( $\mathrm{n}=10$ in each group): the sham-operation group, the sham-operation and treadmill exercise group, the Huntington's disease-induced group, and the Huntington's disease-induced and treadmill exercise group.

\section{Induction of Huntington's disease model}

Huntington's disease was induced using a previously described procedure (Lee et al., 2006; Kim et al., 2015). In brief, the rats were anesthetized with Zoletil $50^{\circledR}(10 \mathrm{mg} / \mathrm{kg}$, i.p.; Vibac Laboratories, Carros, France) and prepared for surgery. When the rat was unresponsive, the head was shaved and placed into a digital stereotaxic device (Benchmark Deluxe ${ }^{\mathrm{TM}}$; MyNeurolab, St. Louis, MO, USA). They were positioned in a stereotaxic apparatus, and quinolinic acid-induced lesion was made by unilateral intrastriatal injection of quinolinic acid ( $2 \mu \mathrm{L}$ of $100 \mathrm{nmol}$ ) using a Hamilton syringe at the following coordinates: AP $+0.7 \mathrm{~mm}, \mathrm{~L}+2.8 \mathrm{~mm}$ and V $-6.0 \mathrm{~mm}$, from bregma. Free access to food and water was allowed after recovery from anesthesia. The rats in the sham-operation group and in the sham-operation and treadmill exercise group were treated identically, except injection with the same volume of normal saline.

\section{Treadmill exercise protocol}

The rats in the treadmill exercise groups were subjected to run on a treadmill for 30 min once a day during 14 days, starting two days after surgery. Exercise load consisted of running at a speed of 2 meters $/ \mathrm{min}$ for the first $5 \mathrm{~min}$, at a speed of 5 meters $/ \mathrm{min}$ for the next $5 \mathrm{~min}$, and then at a speed of 8 meters/min for the last $20 \mathrm{~min}$, with the $0^{\circ}$ inclination.

\section{Radial 8-arm maze test}

Spatial learning ability was tested using a radial 8-arm maze apparatus, as the previously described method (Seo et al., 2013; Jeong et al., 2014). The radial 8-arm maze apparatus consisted of a central octagonal plate $(30 \mathrm{~cm}$ in diameter) and radiating eight arms $(50 \mathrm{~cm}$ in length and $10 \mathrm{~cm}$ in width). The apparatus was placed $1 \mathrm{~m}$ above the floor. A small receptacle filled with water (3 $\mathrm{cm}$ in diameter and $1 \mathrm{~cm}$ in depth) was located at the end of the arms. The rats were trained three times before the spatial learning ability test. The rats deprived of water for $24 \mathrm{~h}$ were allowed to explore the water and to drink for $5 \mathrm{~min}$. On the 14 days after starting of treadmill exercise, the spatial learning ability test was performed. The time spent in seeking water at the end of the arms was counted. The test was terminated when a rat found water in all eight arms or over 6 min elapsed. Re-entering to the previously visited arms was counted as the error. In addition, the number of correct choice before the first error was counted.

\section{Rota-rod test}

On the 14 days after starting of treadmill exercise, we per- 
formed rota-rod (Biological Research Apparatus, Ugo Basile, Varese, Italy) test to measure motor coordination and balance, according to the previously described method (Kim et al., 2013). Each rat was placed in a separate compartment on the rotating rod (diameter $7 \mathrm{~cm}$ ). Velocity of the rod was set to $15 \mathrm{rpm}$ constantly. The time of latency until fall off was automatically recorded by magnetic trip plates. To eliminate stress and fatigue, the rats were given $300 \mathrm{sec}$ as a maximum cutoff latency.

\section{Tissue preparation}

The rats were sacrificed immediately after determining rota-rod test. To begin the sacrifice process, the animals were fully anesthetized using Zoletil $50^{\circledast}$ (10 mg/kg, i.p.; Vibac Laboratories, Carros, France). The anesthetized rats were transcardially perfused with $50 \mathrm{mM}$ phosphate-buffered saline (PBS), and fixed with a freshly prepared solution consisting of $4 \%$ paraformaldehyde (PFA) in $100 \mathrm{mM}$ phosphate buffer (PB) at $\mathrm{pH}$ 7.4. Brains were dissected, post-fixed in the same fixative overnight, and transferred to $30 \%$ sucrose for cryoprotection. Coronal sections of 40 $\mu \mathrm{m}$ thickness were made with a freezing microtome (Leica, Nussloch, Germany). The sections were finally mounted onto gelatin-coated slides. The slides were air-dried overnight at room temperature, and the coverslips were mounted using Permount ${ }^{\circledR}$ (Fisher Scientific, Fair Lawn, NJ, USA).

\section{Caspase-3 immunohistochemistry}

Caspase- 3 immunohistochemistry was performed, according to a previously described method (Seo et al., 2013). In brief, the sections were incubated overnight with mouse anti-caspase-3 antibody (1:500; Santa Cruz Biotechnology, Santa Cruz, CA, USA) and then they were incubated for another $1 \mathrm{~h}$ with the biotinylated mouse secondary antibody. The bound secondary antibody was then amplified using a Vector Elite $\mathrm{ABC} \mathrm{kit}^{\circledR}$ (1:100; Vector Laboratories, Burlingame, CA, USA). The antibody-biotin-avidin-peroxidase complex was visualized using $0.03 \%$ 3,3'-diaminobenzidine (DAB). The sections were finally mounted onto gelatin-coated slides. The slides were air-dried overnight at room temperature, and the coverslips were mounted using Permount ${ }^{\oplus}$ (Fisher Scientific).

\section{Western blot analysis of Bax and $\mathrm{Bcl}-2$ expressions}

The hippocampal tissues were collected, and then were immediately frozen at $-70^{\circ} \mathrm{C}$. The hippocampal tissues were homogenized on ice, and lysed in a lysis buffer containing $50 \mathrm{mM}$ HEPES ( $\mathrm{pH}$ 7.5), $150 \mathrm{mM} \mathrm{NaCl}, 10 \%$ glycerol, $1 \%$ Triton X-100, 1
mM PMSF, 1 mM EGTA, 1.5 mM MgCl $26 \mathrm{H}_{2} \mathrm{O}, 1 \mathrm{mM}$ sodium orthovanadate, and $100 \mathrm{mM}$ sodium flouride. Protein content was measured using a Bio-Rad colorimetric protein assay kit (Bio-Rad, Hercules, CA, USA). Protein $(30 \mu \mathrm{g})$ was separated on SDS-polyacrylamide gels and transferred onto a nitrocellulose membrane.

Mouse beta-actin antibody (1:500; Santa Cruz Biotechnology), mouse Bcl-2 antibody (1:1,000; Santa Cruz Biotechnology), and mouse Bax antibody (1:1,000; Santa Cruz Biotechnology) were used as the primary antibodies. Horseradish peroxidase-conjugated anti-mouse antibodies for beat-actin, Bax, and Bcl-2 (1:3,000; Amersham Pharmacia Biothech GmbH, Freiburg, Germany) were used as the secondary antibodies.

Experiment was performed in normal lab conditions and at room temperature except membrane transfer. Membrane transfer was performed at $4^{\circ} \mathrm{C}$ with the cold pack and pre-chilled buffer. Band detection was performed using the enhanced chemiluminescence (ECL) detection kit (Santa Cruz Biotechnology).

\section{Data analysis}

The number of caspase-3-positive cells in the hippocampal dentate gyrus was counted hemilaterally under a light microscope (Olympus, Tokyo, Japan), and expressed as the number of cells per $\mathrm{mm}^{2}$ in the hippocampal dentate gyrus. To compare the relative expressions of $\mathrm{Bax}$ and $\mathrm{Bcl}-2$, the detected bands were calculated densitometrically using Image-Pro ${ }^{\circledR}$ Plus software (Media Cybernetics, Silver Spring, MD, USA). Statistical analysis was performed using one-way ANOVA followed by Duncan's posthoc test. The results are presented as the mean \pm standard error of the mean (SEM). Significance was set as $P<0.05$.

\section{RESULTS}

\section{Effect of treadmill exercise on spatial learning ability in the radial 8-arm maze test}

The effect of treadmill exercise on the spatial learning ability in the radial 8-arm maze test is presented in Fig. 1. The number of correct choice before the first error was $5.12 \pm 0.45$ in the sham-operation group, $5.87 \pm 0.23$ in the sham-operation and exercise group, $2.87 \pm 0.23$ in the Huntington's disease-induced group, and $4.75 \pm 0.42$ in the Huntington's disease-induced and treadmill exercise group. The number of error made before eight successful performances was $4.87 \pm 0.66$ in the sham-operation group, $3.12 \pm 0.68$ in the sham-operation and exercise group, $8.87 \pm 0.67$ in the Huntington's disease-induced group, and $5.75 \pm 0.83$ in the Huntington's disease-induced and treadmill 

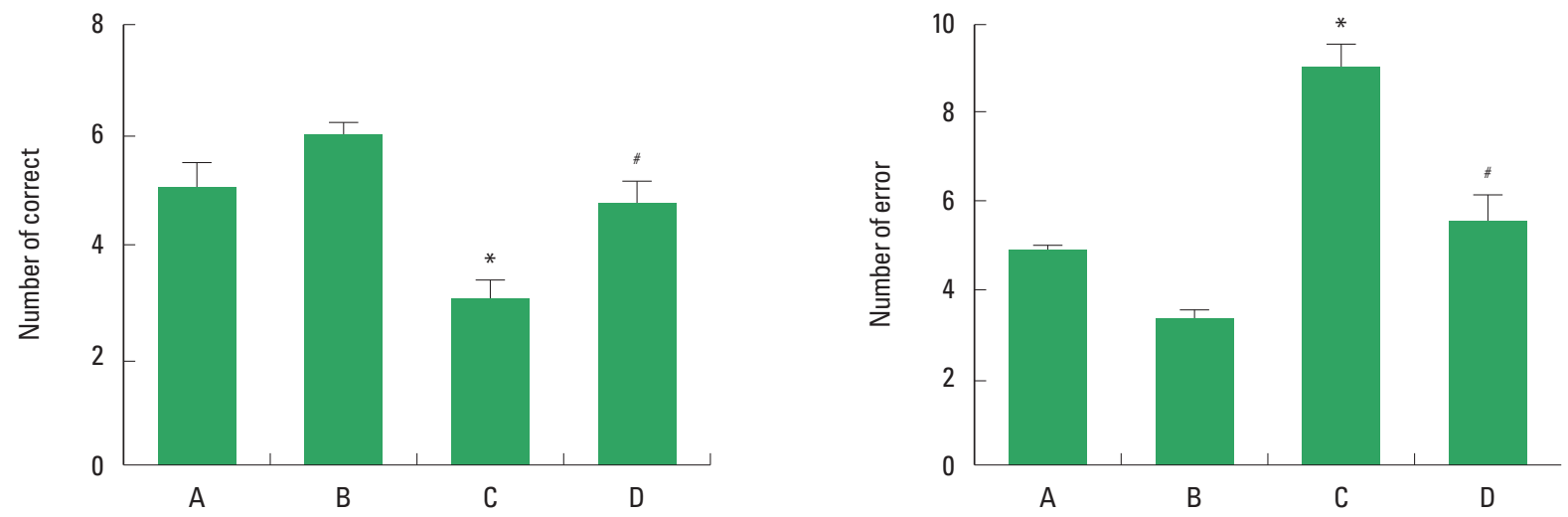

Fig. 1. Effect of treadmill exercise on the spatial learning ability in the radial 8-arm maze test. Left: Number of correct choice. Right: Number of error. (A) Sham-operation group, (B) sham-operation and treadmill exercise group, (C) Huntington's disease-induced group, (D) Huntington's disease-induced and treadmill exercise group. ${ }^{*}$ represents $P<0.05$ compared to the sham-operation group. "represents $P<0.05$ compared to the Huntington's disease-induced group. The data are expressed as the mean \pm standard error of the mean (SEM).

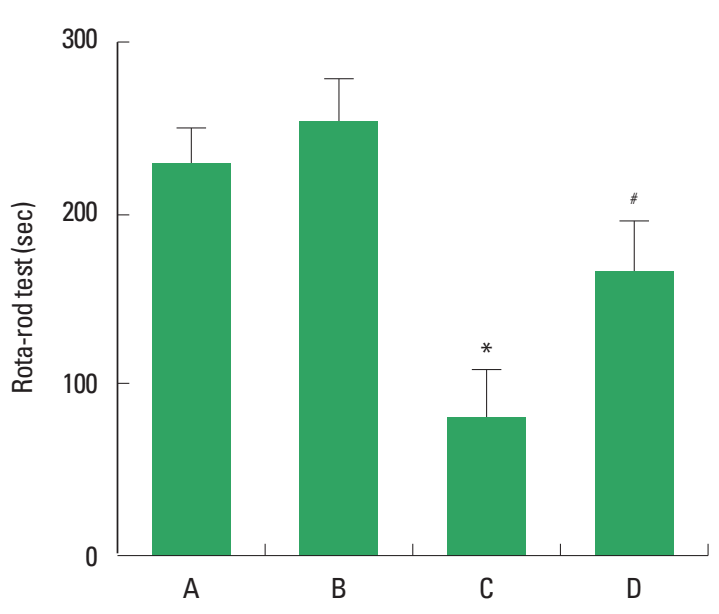

Fig. 2. Effect of treadmill exercise on the motor coordination in the rota-rod test. (A) Sham-operation group, (B) sham-operation and treadmill exercise group, (C) Huntington's disease-induced group, (D) Huntington's disease-induced and treadmill exercise group. ${ }^{*}$ represents $P<0.05$ compared to the sham-operation group. "represents $P<0.05$ compared to the Huntington's disease-induced group. The data are expressed as the mean \pm standard error of the mean (SEM).

exercise group. The present results indicate that spatial leaning ability was deteriorated by inducing Huntington's disease $(P<0.05)$, however, treadmill exercise alleviated Huntington's disease-induced deterioration of spatial leaning ability $(P<0.05)$.

\section{Effect of treadmill exercise on the motor coordination in the rota-rod test}

The effect of treadmill exercise on the motor coordination in the rota-rod test is presented in Fig. 2. The time score was $225.25 \pm 25.61 \mathrm{sec}$ in the sham-operation group, $256.25 \pm 21.44$ sec in the sham-operation and exercise group, $81.87 \pm 17.15 \mathrm{sec}$ in the Huntington's disease-induced group, and $166.43 \pm 30.71 \mathrm{sec}$ in the Huntington's disease-induced and treadmill exercise group. The present results indicate that motor coordination was reduced by inducing Huntington's disease $(P<0.05)$, however, treadmill exercise recovered motor coordination in the Huntington's disease rats $(P<0.05)$.

Effect of treadmill exercise on the caspase-3 expression in the hippocampal dentate gyrus

The effect of treadmill exercise on the caspase- 3 expression in the hippocampal dentate gyrus is presented in Fig. 3. The number of caspase-3-positive cells in the hippocampal dentate gyrus was $12.09 \pm 2.88$ in the sham-operation group, $11.50 \pm 2.90$ in the sham-operation and exercise group, 56.19 \pm 9.06 in the Huntington's disease-induced group, and $37.37 \pm 6.71$ in the Huntington's disease-induced and treadmill exercise group. The present results indicate that caspase- 3 expression in the hippocampal dentate gyrus was increased by inducing Huntington's disease $(P<0.05)$, however, treadmill exercise suppressed caspase- 3 expression in the Huntington's disease rats $(P<0.05)$.

\section{Effect of treadmill exercise on the expressions of Bax and Bcl-2 in the hippocampus}

The effect of treadmill exercise on the expressions of Bax and $\mathrm{Bcl}-2$ in the hippocampus is presented in Fig. 4. When the level of $\mathrm{Bax}(21 \mathrm{kDa})$ in the sham-operation group was set as 1.00 , the level of Bax was $0.78 \pm 0.01$ in the sham-operation and exercise group, $1.22 \pm 0.02$ in the Huntington's disease-induced group, and $1.14 \pm 0.03$ in the Huntington's disease-induced and tread- 

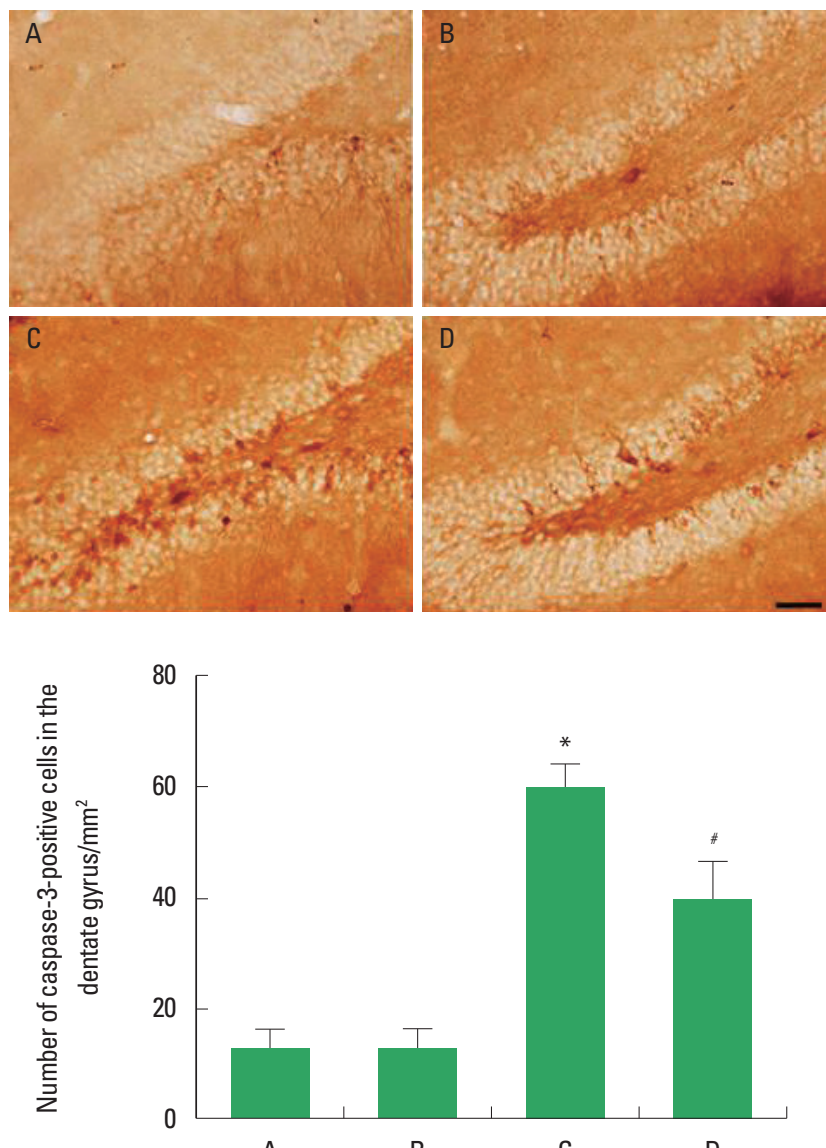

A
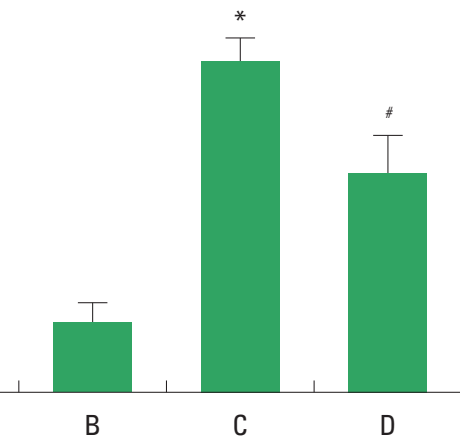

Fig. 3. Effect of treadmill exercise on the caspase-3 expression in the hippocampal dentate gyrus. Upper: Photomicrographs of caspase-3-positive cells. The scale bar $50 \mu \mathrm{m}$. Lower: Number of caspase-3-positive cells in each group. (A) Sham-operation group, (B) sham-operation and treadmill exercise group, (C) Huntington's disease-induced group, (D) Huntington's disease-induced and treadmill exercise group. * represents $P<0.05$ compared to the sham-operation group. "represents $P<0.05$ compared to the Huntington's disease-induced group. The data are expressed as the mean \pm standard error of the mean (SEM).

mill exercise group. The present results indicate that Bax expression in the hippocampus was increased by inducing Huntington's disease $(P<0.05)$, however, treadmill exercise decreased Bax expression in the Huntington's disease rats $(P<0.05)$.

When the level of $\mathrm{Bcl}-2(26 \mathrm{kDa})$ in the sham-operation group was set as 1.00, the level of $\mathrm{Bcl}-2$ was $1.08 \pm 0.04$ in the sham-operation and exercise group, $0.87 \pm 0.01$ in the Huntington's disease-induced group, and $0.97 \pm 0.02$ in the Huntington's disease-induced and treadmill exercise group. The present results indicate that $\mathrm{Bcl}-2$ expression in the hippocampus was decreased by inducing Huntington's disease $(P<0.05)$, however, treadmill exercise increased $\mathrm{Bcl}-2$ expression in the Huntington's disease rats
$(P<0.05)$.

When the ratio of $\mathrm{Bax} / \mathrm{Bcl}-2$ in the sham-operation group was set as 1.00 , the ratio of $\mathrm{Bax} / \mathrm{Bcl}-2$ was $0.73 \pm 0.03$ in the sham-operation and exercise group, $1.40 \pm 0.04$ in the Huntington's disease-induced group, and $1.17 \pm 0.05$ in the Huntington's disease-induced and treadmill exercise group. The present results indicated that ratio of $\mathrm{Bax} / \mathrm{Bcl}-2$ in the hippocampus was increased by inducing Huntington's disease $(P<0.05)$, however, treadmill exercise decreased the ratio of $\mathrm{Bax} / \mathrm{Bcl}-2$ in the Huntington's disease rats $(P<0.05)$.

\section{DISCUSSION}

Intrastriatal administration of quinolinic acid induced Huntington's disease-like symptoms, such as reduction in body weight and motor function (locomotor activity, rota-rod performance, and beam walk test) (Kalonia et al., 2011). In the present results, spatial learning ability and motor coordination were deteriorated by intrastriatal injection of quinolinic acid. Treadmill exercise exerted ameliorating effect on quinolinic acid-induced deterioration of spatial learning ability and motor coordination. These results demonstrated that treadmill exercise ameliorated symptoms of quinolinic acid-induced Huntington's disease.

In the transgenic mice models of Huntington's disease, upregulation of caspase- 1 and caspase- 3 mRNA was observed, and inhibition on caspase- 1 and caspase- 3 showed effectiveness on the improvement of symptoms of Huntington's disease (Chen et al., 2000). Teles et al. (2008) reported that Bax level in the cortex of R6/1 transgenic (TGN) mice was increased, and the increment in Bax was correlated with the elevation in the number of apoptotic nuclei. They suggested that Bax expression contributed to the progression of Huntington's disease (Teles et al., 2008). Induction of Bcl-2 immunoreactivity and down-regulation of Bax immunoreactivity contributed to the neuroprotective effect on the quinolinic acid model of Huntington's disease (Patassini et al., 2008). In the present results, $\mathrm{Bcl}-2$ expression in the hippocampus was decreased and expressions of casepase- 3 and Bax in the hippocampus were increased in the quinolinic acid-induced Huntington's disease rats. Treadmill exercise increased $\mathrm{Bcl}-2$ expression and decreased casepase- 3 and Bax expressions in the Huntington's disease rats. These results demonstrated that treadmill exercise suppressed quinolinic acid-induced apoptosis in the hippocampus.

Anti-apoptotic and neuronal maturation effects of exercise against various neuropsychiatric diseases are well documented (Baek et al., 2012; Kim et al., 2010; Sim, 2014). Pang et al. 


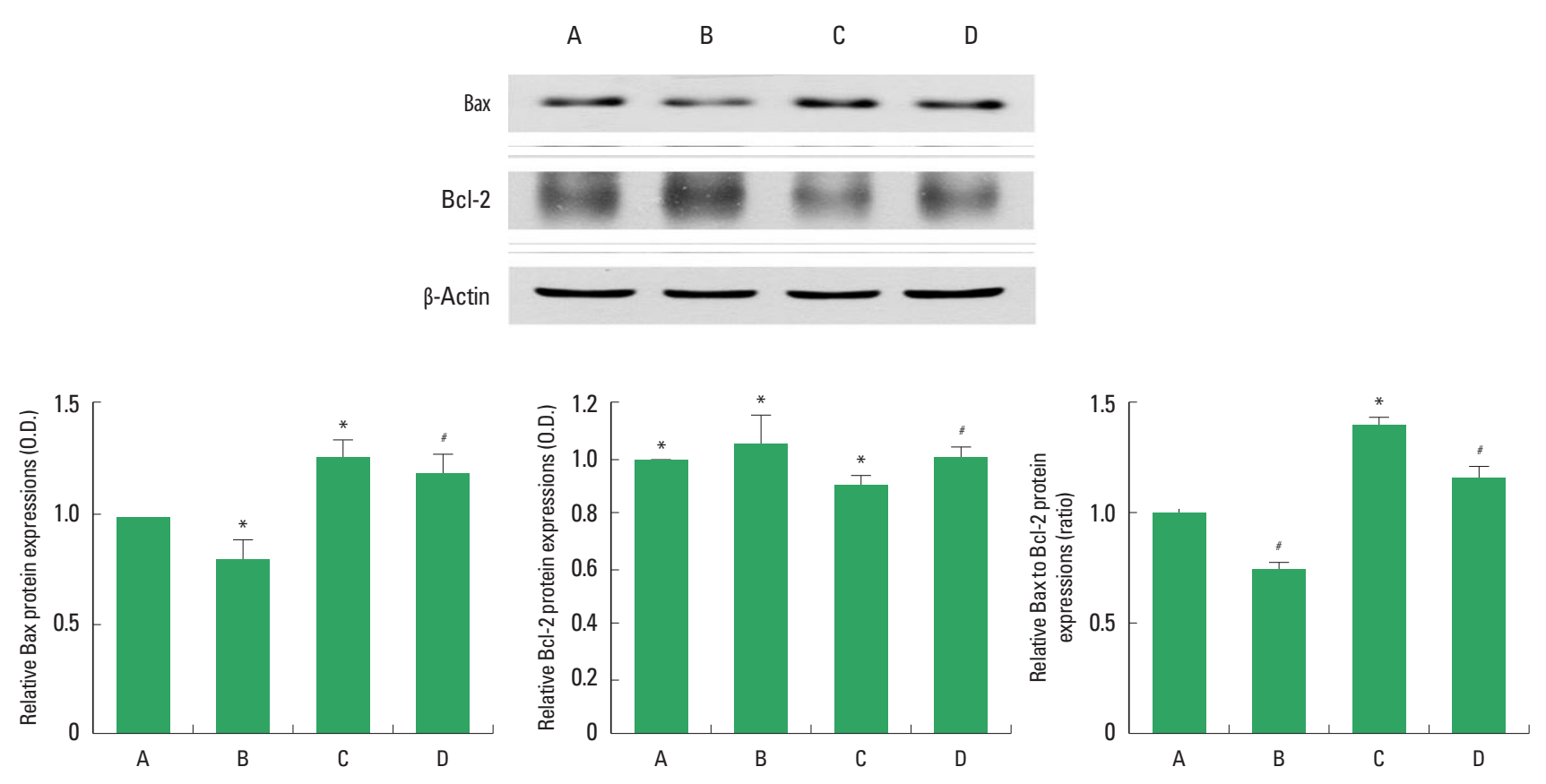

Fig. 4. Effect of treadmill exercise on the Bax and Bcl-2 expressions in the hippocampus. Upper: Western blot analysis of Bax and Bcl-2 in the hippocampus. Left: The optical density of Bax expression in each group. Middle: The optical density of Bcl-2 expression in each group. Right: The Bax/Bcl-2 ratio in each group. (A) Sham-operation group, (B) sham-operation and treadmill exercise group, (C) Huntington's disease-induced group, (D) Huntington's disease-induced and treadmill exercise group. * represents $P<0.05$ compared to the sham-operation group. " represents $P<0.05$ compared to the Huntington's disease-induced group. The data are expressed as the mean \pm standard error of the mean (SEM).

(2006) showed that voluntary physical exercise delayed the onset of Huntington's disease and the decline in cognitive ability. Zajac et al. (2010) demonstrated that brain-derived neurotrophic factor (BDNF) mRNA was reduced in the hippocampus of both male and female Huntington's disease mice, and wheel-running increased BDNF gene expression in all groups of mice except male Huntington's disease mice. Treadmill exercise improved shortterm memory through enhancing cell proliferation in the hippocampal dentate gyrus of the quinolinic acid-induced Huntington's disease rats (Kim et al., 2015).

The present results showed that treadmill exercise might ameliorate quinolinic acid-induced loss of spatial learning ability and motor coordination by suppressing apoptosis in the hippocampus. These results support the possibility that exercise may provide a potential therapeutic strategy for the alleviation of symptoms of Huntington's disease.

\section{CONFLICT OF INTEREST}

No potential conflict of interest relevant to this article was reported.

\section{ACKNOWLEDGMENTS}

This work was supported by the National Research Foundation of Korea Grant funded by the Korean Government (NRF-2010327-G00099).

\section{REFERENCES}

Baek SS, Jun TW, Kim KJ, Shin MS, Kang SY, Kim CJ. Effects of postnatal treadmill exercise on apoptotic neuronal cell death and cell proliferation of maternal-separated rat pups. Brain Dev 2012;34:45-56.

Beal MF, Kowall NW, Ellison DW, Mazurek MF, Swartz KJ, Martin JB. Replication of the neurochemical characteristics of Huntington's disease by quinolinic acid. Nature 1986;321:168-171.

Chen M, Ona V, Li M, Ferrante R, Fink K, Zhu S, Bian J, Guo L, Farrell L, Hersch S, Hobbs W, Vonsattel J, Cha J, Friedlander R. Minocycline inhibits caspase- 1 and caspase- 3 expression and delays mortality in a transgenic mouse model of Huntington disease. Nat Med 2000;6:797801.

Estrada Sánchez AM, Mejía-Toiber J, Massieu L. Excitotoxic neuronal death and the pathogenesis of Huntington's disease. Arch Med Res 2008;39:265-276. 
Haik KL, Shear DA, Schroeder U, Sabel BA, Dunbar GL. Quinolinic acid released from polymeric brain implants causes behavioral and neuroanatomical alterations in a rodent model of Huntington's disease. Exp Neurol 2000;163:430-439.

Hickey M, Chesselet M. Apoptosis in Huntington's disease. Prog Neuropsychopharmacol Biol Psychiatry 2003;27:255-265.

Jeong HI, Ji ES, Kim SH, Kim TW, Baek SB, Choi SW. Treadmill exercise improves spatial learning ability by enhancing brain-derived neurotrophic factor expression in the attention-deficit/hyperactivity disorder rats. J Exerc Rehabil 2014;10:162-167.

Jørgensen JR, Emerich DF, Thanos C, Thompson LH, Torp M, Bintz B, Fjord-Larsen L, Johansen TE, Wahlberg LU. Lentiviral delivery of meteorin protects striatal neurons against excitotoxicity and reverses motor deficits in the quinolinic acid rat model. Neurobiol Dis 2011;41:160168.

Kalonia H, Kumar P, Kumar A. Licofelone attenuates quinolinic acid induced Huntington like symptoms: possible behavioral, biochemical and cellular alterations. Prog Neuropsychopharmacol Biol Psychiatry 2011;35:607-615.

Kim H, Heo HI, Kim DH, Ko IG, Lee SS, Kim SE, Kim BK, Kim TW, Ji ES, Kim JD, Shin MS, Choi YW, Kim CJ. Treadmill exercise and methylphenidate ameliorate symptoms of attention deficit/hyperactivity disorder through enhancing dopamine synthesis and brain-derived neurotrophic factor expression in spontaneous hypertensive rats. Neurosci Lett 2011;504:35-39.

Kim JE, Shin MS, Seo TB, Ji ES, Baek SS, Lee SJ, Park JK, Kim CJ. Treadmill exercise ameliorates motor disturbance through inhibition of apoptosis in the cerebellum of valproic acid-induced autistic rat pups. Mol Med Rep 2013;8:327-334.

Kim SE, Ko IG, Kim BK, Shin MS, Cho S, Kim CJ, Kim SH, Baek SS, Lee EK, Jee YS. Treadmill exercise prevents aging-induced failure of memory through an increase in neurogenesis and suppression of apoptosis in rat hippocampus. Exp Gerotol 2010;45:357-365.

Kim YM, Ji ES, Kim SH, Kim TW, Ko IG, Jin JJ, Kim CJ, Kim TW, Kim $\mathrm{DH}$. Treadmill exercise improves short-term memory by enhancing hippocampal cell proliferation in quinolinic acid-induced Huntington's disease rats. J Exerc Rehabil 2015;11:5-11.

Kuhn HG, Biebl M, Wilhelm D, Li M, Friedlander RM, Winkler J. Increased generation of granule cells in adult $\mathrm{Bcl}$-2-overexpressing mice: a role for cell death during continued hippocampal neurogenesis. Eur J Neurosci 2005;22:1907-1915.

Kuwana T, Newmeyer DD. Bcl-2-family proteins and the role of mitochondria in apoptosis. Curr. Opin. Cell Biol 2003;15:691-699.
Lang R, Koegel LK, Ashbaugh K, Regester A, Ence W, Smith W. Physical exercise and children with autism spectrum disorders: a systematic review. Res Autism Spectr Disord 2010;4:565-576.

Lee ST, Park JE, Lee K, Kang L, Chu K, Kim SU, Kim M, Roh JK. Noninvasive method of immortalized neural stem-like cell transplantation in an experimental model of Huntington's disease. J Neurosci Methods 2006;152:250-254.

Nuñez G, Benedict MA, Hu Y, Inohara N. Caspases: the proteases of the apoptotic pathway. Oncogene 1998;17:3237-3245.

Pang TY, Stam NC, Nithianantharajah J, Howard ML, Hannan AJ. Differential effects of voluntary physical exercise on behavioral and brain-derived neurotrophic factor expression deficits in Huntington's disease transgenic mice. Neuroscience 2006;141: 569-584.

Patassini S, Giampà C, Martorana A, Bernardi G, Fusco FR. Effects of simvastatin on neuroprotection and modulation of $\mathrm{Bcl}-2$ and $\mathrm{BAX}$ in the rat quinolinic acid model of Huntington's disease. Neurosci Lett 2008;448:166-169.

Petersén A, Mani K, Brundin P. Recent advances on the pathogenesis of Huntington's disease. Exp Neurol 1999;157:1-18.

Petrus C, Adamson SR, Block L, Einarson SJ, Sharifnejad M, Harris SR. Effects of exercise interventions on stereotypic behaviours in children with autism spectrum disorder. Physiother Can 2008;60:134-145.

Schwarcz R, Guidetti P, Sathyasaikumar KV, Muchowski PJ. Of mice, rats and men: revisiting the quinolinic acid hypothesis of Huntington's disease. Prog Neurobiol 2010;90:230-245.

Seo TB, Cho HS, Shin MS, Kim CJ, Ji ES, Baek SS. Treadmill exercise improves behavioral outcomes and spatial learning memory through up-regulation of reelin signaling pathway in autistic rats. J Exerc Rehabil 2013;9:220-229.

Sim YJ. Treadmill exercise alleviates impairment of spatial learning ability through enhancing cell proliferation in the streptozotocin-induced Alzheimer's disease rats. J Exerc Rehabil 2014;10:81-88.

Teles AV, Rosenstock TR, Okuno CS, Lopes GS, Bertoncini CR, Smaili SS. Increase in bax expression and apoptosis are associated in Huntington's disease progression. Neurosci Lett 2008;438:59-63.

Thompson CB. Apoptosis in the pathogenesis and treatment of disease. Science 1995;267:1456-1462.

Zajac MS, Pang TY, Wong N, Weinrich B, Leang LS, Craig JM, Saffery R, Hannan AJ. Wheel running and environmental enrichment differentially modify exon-specific BDNF expression in the hippocampus of wild-type and pre-motor symptomatic male and female Huntington's disease mice. Hippocampus 2010;20:621-636. 